\title{
Metabolism-based Modelling for Performance Assessment of Water Supply System: A Case Study of Reggio Emilia, Italy
}

\author{
T. Liserra*, K. Benzedian**, R Ugarelli***, R. Bertozzi****, V. Di Federico*, Z. Kapelan** \\ * Dipartimento di Ingegneria Civile, Chimica, Ambientale e dei Materiali (DICAM), Università di Bologna, Viale \\ Risorgimento, 2, 40136 Bologna, Italy, email: tonino.liserra@unibo.it \\ ** Centre for Water Systems, College of Engineering, Mathematics and Physical sciences, University of Exeter, Exeter, \\ EX4 4QF, UK. \\ *** SINTEF Building and Infrastructure, Forskningsveien 3b, NO-0314 Oslo, Norway \\ **** IREN Acqua Gas Gruppo IREN. Via Nubi di Magellano 30, 42123 Reggio Emilia, Italy.
}

\begin{abstract}
A new class of conceptual simulation tools, as a complement to physically based models, is becoming available to simulate the whole water cycle in urban areas for strategic planning often involving the allocation of great amount of financial resources. These simulation tools are required to estimate the impact of the today decisions on the system performance over the next decades and to compare and rank different intervention strategies. To achieve this, this paper aims to build the metabolism-based modelling of real water supply system using the recently developed WaterMet ${ }^{2}$ model in order to evaluate long-term performance metrics for possible intervention strategies. This metabolism-based approach was demonstrated for evaluation of the water supply system of Reggio Emilia, Italy, which is one of the demonstration case studies in the EU TRUST project. Based on the strains imposed by pressing challenges (here population growth) two intervention strategies were analysed. The results obtained show that the built and calibrated WaterMet ${ }^{2}$ model allows a broader understanding of the impacts of alternative intervention strategies taking into account multidimensional aspects of the sustainability beside conventional service performance.
\end{abstract}

Keywords: Urban water systems, TRUST, WaterMet ${ }^{2}$, Intervention strategy, Sustainability.

\section{INTRODUCTION}

Urban water systems (UWS) play an important role in the great sustainability challenge of reconstructing cities (Kennedy et al. 2011). An efficient future plan for sustainable use of water and other resources in a UWS needs to take into account their long-term impact on other flows in the UWS such as materials, energy and costs, in addition to the ability to meet service goals of water supply. Some recently developed tools which have strived to attain this aim are Aquacycle developed by Mitchell et al. (2001) as a water balance model, UWOT by Makropoulos et al. (2008) as a sustainable water management tool for selection of combinations of water-saving technologies, $U V Q$ by Mitchell and Diaper (2010) as a further modified version of Aquacycle to include contaminant and energy flow, and $C W B$ by Mackay and Last (2010) as a city water balance model. However, none of these models can be considered as a holistic systemic perspective for: i) analysing the main resource flows and their impacts on the future performance of UWS; ii) examining intervention strategies for long-term planning in UWS. This approach can be envisaged through a metabolism based modelling. Metabolism in UWS refers to the fluxes and conversion processes related to all kinds of water flows, materials and energy in the UWS, which are necessary to fulfil expected functions (Venkatesh and Brattebø, 2011). Accounting for the metabolism dynamics enables decision makers to identify the critical components which have major impact on different sustainability dimensions. This will also allow investigating various intervention strategies which concurrently save water, energy, chemicals and costs and also minimise negative environmental impacts. The metabolism concept calls for a systematic engineering approach to the examination, understanding and improvement of urban water services, and it offers the 
possibility of a well-structured quantitative analysis of how the key system characteristics are interrelated. All this approach is currently encapsulated in a recently developed concept of the WaterMet ${ }^{2}$ model which simulates metabolism based performance of UWS over a long-term planning horizon (Behzadian et al. 2014). The performance indicators calculated in WaterMet ${ }^{2}$ can also be used to support risk-based indicators which are useful for a more comprehensive analysis in UWS (Ugarelli et al. 2014a, 2014b). WaterMet ${ }^{2}$ has been developed through TRUST (TRansitions to the Urban Water Services of Tomorrow), a four year research project funded by the European Union (www.trust-i.net/). The ambition of TRUST is to deliver co-produced knowledge to enable water utilities to achieve a sustainable future without compromising service quality. The work presented in this paper is one of the products of TRUST to deliver this ambition. The paper presents the application of the WaterMet ${ }^{2}$ model to the urban water supply system of the city of Reggio Emilia (Italy), managed by IREN Spa. This system, serving 170,000 inhabitants, is one of the demonstration case studies of TRUST project. Therefore, this study aims to: i) demonstrate the application of the above metabolism concept using the case study; ii) contribute to the evaluation of the level of sustainability in the water supply system of Reggio Emilia; iii) highlight the use of $\mathrm{WaterMet}^{2}$ as provider of additional information, in respect to the traditional simulation tools, to the selection process of the most appropriate intervention strategies to overcome the future strain and challenges of the water supply system. The paper is organised as follows: the main features of WaterMet ${ }^{2}$ model used in this study are first introduced in the next section followed by a description of the case study of Reggio Emilia and its characteristics. Next, the built WaterMet ${ }^{2}$ model for Reggio Emilia case is illustrated. The results of the simulated model are then presented and discussed. Finally, the conclusions are drawn and some recommendations for further research are made.

\section{URBAN WATER METABOLISM MODEL: WATERMET ${ }^{2}$}

WaterMet ${ }^{2}$ has been developed to calculate indicators for assessment of the sustainability performance in UWS (Behzadian et al. 2013). WaterMet ${ }^{2}$ is a conceptual, simulation type, mass-balance-based, integrated UWS model which quantifies metabolism-related key performance of UWS with focus on sustainability-related issues over a long-term planning horizon (Behzadian et al., 2014). WaterMet ${ }^{2}$ tracks down a number of metabolism based fluxes within the operating phase of the UWS by using a range of input mass fluxes (e.g. water inflow, energy and chemicals used). This, in turn, will enable WaterMet ${ }^{2}$ to calculate metabolism related indicators in the UWS including principal water-related flows (e.g. water demand and supply), environmental-related fluxes (e.g. GHG emissions), cost flows and so on. WaterMet ${ }^{2}$ model is able to simulate the main UWS components. WaterMet ${ }^{2}$ is a distributed model which allows the user to define any arbitrary number of each type of the UWS components (e.g. water mains, service reservoirs and sub-catchment). Moreover, WaterMet ${ }^{2}$ can support various types of water demands profile and water recycling options. WaterMet ${ }^{2}$ is also able to simulate rainwater harvesting and grey water recycling schemes in the UWS. WaterMet ${ }^{2}$ can also support the flows of chemical consumption, sludge and resource recovery for treatment purposes. All this, in turn, provides flexibility for WaterMet ${ }^{2}$ to simply model various fundamental intervention strategies and thus enables a decision support system to evaluate them over a long-term planning horizon. This kind of flexibility may not be easily achieved through other physically based models due mainly to extensive and detailed data required for modelling new intervention options and limited number of calculated performance indicators related to sustainability framework in those models. These interventions can include either new UWS components for new developments or technological improvements in the UWS components (e.g. energy-efficient or water-efficient equipment). Further details of WateMet ${ }^{2}$ modelling processes and assumptions can be found in Behzadian et al. (2013) and Behzadian et al. (2014). 


\section{TRUST APPROACH TO WATER SYSTEM SUSTANABILITY}

The TRUST approach to obtain a better level of sustainability in the UWS can be summarized as follows: a) assessment of the current sustainability level; b) setting of the sustainability target at the strategic horizon; c) definition of a set of suitable interventions to match the targets in agreement with stakeholders expectations; d) use of the available tools (e.g. metabolism model, risk manager, decision support, etc.) to find the best combination of interventions (roadmap); e) implementation of the roadmap; f) evaluation of sustainability results at intermediate time horizons; g) fine-tuning the interventions to be done; h) adjusting of the sustainability targets and i) selection of additional interventions if needed (Di Federico et al., 2014).

WaterMet ${ }^{2}$ is used here as a conceptual model and tool which is able to calculate several metrics related to the abovementioned sustainability criteria in strategic long-term planning horizon within the sustainability framework adopted in the TRUST project (Alegre et al., 2012). Also note that the definition of the sustainability is extended here by including two additional domains, to take into account the assets and the governance characterizing the UWS. In the TRUST perspective, the main goal to be achieved at the strategic horizon is being more sustainable than now. Therefore, all the interventions (structural and non-structural ones) have to be aimed to this purpose. Objectives and metrics are established for a given UWS through a participate process that involves, among the others, the water company, water authorities, stakeholders, research actors and several practitioners. The road map process for the UWS of Reggio Emilia and its main outcomes have been described in (Di Federico et al., 2014).

\section{CASE STUDY}

The sustainability performance assessment of intervention strategies in $\mathrm{WaterMet}^{2}$ is demonstrated in the water supply system of Reggio Emilia city. Reggio Emilia lies in the Po plain in the North of Italy in the western part of the Emilia Romagna region. Its territory has deeply changed in the last decades becoming densely built, with a very high population growth rate due to immigration. It is also home to intensive agricultural practices, livestock farming and a number of medium and small industries, many of them devoted to mechatronic and food transformation. The area is currently facing important challenges, from both a social and an environmental point of view. From the water cycle perspective, the water system operates in a context of financial resources, water and energy scarcity. Outcomes from the analysis tools available in TRUST, as the City profile and the Self-Assessment Tool (Van Leeuwen et al, 2013; Hein et al, 2012) the Reggio Emilia water system shows a good hydraulic and water losses control performances.. In fact, a very effective water losses control policy reduced the undelivered water volume to values lesser than $10 \%$ of the withdrawal ones.. On this basis further reductions of water losses are considered by the water company economically and technically unfeasible. On the other hand the per-capita water consumption is close to the Water Protection Plan of the Emilia Romagna Region and in order to decrease water consumption an adaptation of the user habits is necessary (Pahl-Wostl, 2002; Shove \& Walker, 2010). Unfortunately, this process cannot be controlled by the water company only. For these motivations here this option has not been considered. Hence, a few options, limited also by the scarcity of financial resources, are available to the water company to improve the sustainability performances and thus to cope with external scenarios threatening the UWS. In the future it seems likely that groundwater resources will become insufficient to satisfy the whole increased water demand. Hence, the focus of interventions here is on the water supply ones instead of water demand ones due to 1) strategic level policy of the water company and 2) providing a more reliable water supply in the first instance.

Therefore, some interventions aiming at reducing the pressure on the fresh water sources are advisable. The road-mapping process of the TRUST project (Di Federico, 2014) was carried out in close collaboration with the Water Company and stakeholders. As a result, they highlighted two main 
concerns which have been selected by the water company to be addressed here: (1) the reduction of water withdrawals from groundwater, and (2) the service reliability/resilience due to the tree shaped water supply system layout. Both of them can be exacerbated by water scarcity foreseen in the next decades. Additionally, the consistently increasing population projected (Figure 2) by Italian National Statistics Institute (ISTAT, 2011) would lead to a reduction of the water volume per-capita available for consumption. These concerns lead to the following strategic sustainability objectives: i) to reduce water withdrawals from groundwater; ii) to improve efficiency of water consumption; iii) to improve reliability of water service (Di Federico et al., 2014).

According to the water utility, three intervention strategies have been identified as possible alternatives to improve the sustainability of the water supply system: (1) the Business As Usual (BAU) state (intervention strategy 1); (2) the construction of a new pipeline, located in the northern part of the water supply system, which connects an existing water source (R4 in Figure 1) to Reggio Emilia of the water distribution system to be completed in 3 years (intervention strategy 2); (3) promotion of water consumption in a long term planning horizon by adding water reuse as an alternative non-traditional water source to allow reducing the current pressure on groundwater resources (intervention strategy 3). Note that these intervention strategies suggested by the water company and experts represent different perspectives of improving the UWS reliability and resilience (Behzadian and Kapelan 2015). Other intervention strategies can be proposed for this case study such as rainwater harvesting or greywater reuse but they are relatively derived to water demand or supply interventions. Intervention strategy 2 will contribute to the improvement of the service reliability and therefore the system resilience by adding the redundancy of the water sources available for the city. Also note that the newly connected water source is located in an area with redundant water resources and hence it has no impact on the water available in that area. Also the analysis conducted by WaterMet ${ }^{2}$ here only considers the functions in the long-term operation (i.e. use) phase of the UWS and the environmental impacts of infrastructure activities such as construction, installation and demolition is not analysed due to insignificant environmental impacts (Behzadian and Kapelan 2015). The criteria analysed here are those quantitative metrics which can be calculated by WaterMet ${ }^{2}$. They include technical and environmental objectives including ratio of delivered water demand, energy and GHG emissions over the planning horizon. Other criteria such as social criteria are excluded as they usually need to be quantified by other qualitative methods such as analytical hierarchy analysis (AHP). 


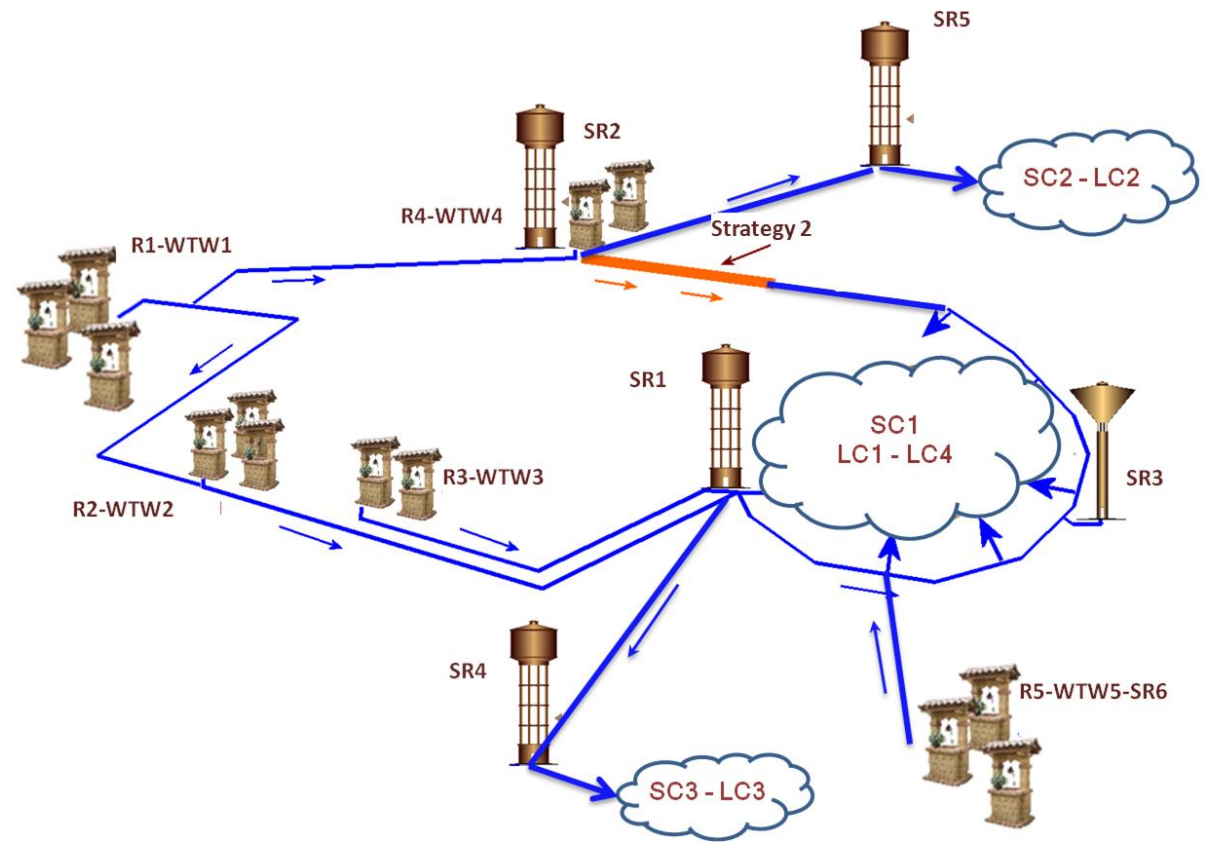

Figure 1 Sketch of the water supply system of Reggio Emilia represented as SC1 area. Adapted from Di Federico et al. (2014); note that here $\mathrm{R}=$ water resource, WTW=water treatment works, $\mathrm{SR}=$ service reservoir, $\mathrm{SC}=$ sub-catchment, $\mathrm{LC}=$ local area.

To demonstrate the capability of the metabolism approach for providing a useful insight into the future planning for the decision makers, this paper analyses and compares the sustainability performance of the water supply system for the first two intervention strategies over a 30 year planning horizon.

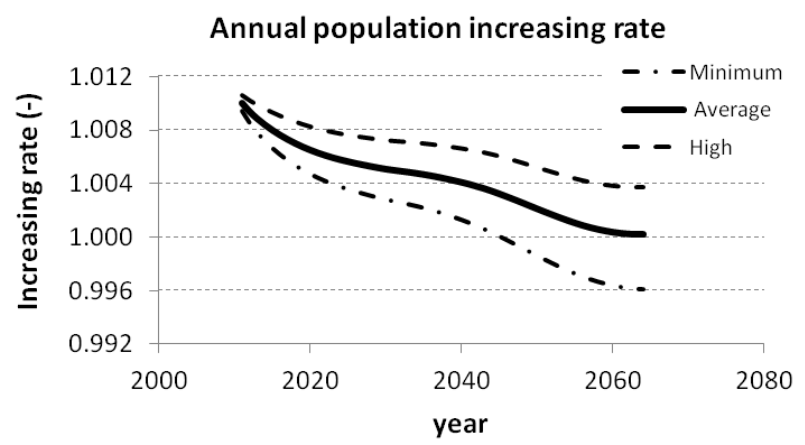

Figure 2 Annual rates of population growth derived for the Emilia Romagna Region (ISTAT, 2011)..

\section{Building the WaterMet ${ }^{2}$ model}

The geographical area of the City is represented in WaterMet ${ }^{2}$ as a collection of sub-catchments (SC) each of which is specified by one or more Local Areas (LC) according with the local physical characteristics of the area and the typology of the water users. The WaterMet ${ }^{2}$ model was built for the existing water supply system of Reggio Emilia (Figure 1), which includes the city itself (SC1) and the neighbouring sub-catchments Roncocesi (SC2 in the figures) and Rivalta (SC3). Four well fields (R1, R2, R3 and R5) provide water to Reggio Emilia and Rivalta, while R4 currently provides water to Roncocesi (Figure 1). As water abstracted from these water sources has a high level of quality, only disinfection is needed to prepare suitable drinking water. In a few cases, a preliminary filtration process is necessary to remove particle components and minerals (R4 and partially $\mathrm{R} 2$ ). Therefore, WTWs (Water Treatment Works) processes are limited only to these two basic functions. The subcatchment Reggio Emilia, represented in WaterMet ${ }^{2}$ by two local areas (LC1 and LC4), accommodates 
totally 151,000 inhabitants; Roncocesi has one local area (LC2) with 85,000 equivalent inhabitants and finally Rivalta is linked to one local area (LC3) with 3,500 equivalent inhabitants. As mentioned above, WTW4 does not contribute to feed LC1. For the purposes of this paper, monthly variations of the water demand were considered by means of average monthly coefficients given in Table 1 . Note that Italian water systems including the one for Reggio Emilia needs to follow a typical monthly water demand pattern such as the one reported in the table. Hence, we used the monthly peal factors of water demand proposed by Arredi (1990) as typical values for this study. However, accurate site-specific data may be required for a further reliable analysis.

Table 1 Adopted Monthly peak factors for water demand for civil usages (Arredi, 1990).

Month Jan. Feb. Mar. Apr. May Jun. Jul. Aug. Sep. Oct. Nov. Dec.

\begin{tabular}{l|llllllllllll}
\hline Coefficients of monthly variations & 0.85 & 0.85 & 0.90 & 0.90 & 1.00 & 1.15 & 1.25 & 1.25 & 1.10 & 1.00 & 0.90 & 0.85 \\
\hline
\end{tabular}

The real conceptualised scheme of the water supply system can be represented in Figure 3(a) according to sketch of the case study shown in Figure 1. This conceptual model is represented as a collection of storage/link types in water supply system, i.e. water resource (R), Water Treatment Works (WTW), service reservoir (SR), sub-catchment (SC), local area (LC) and blue and green links between the storage units representing supply conduits, trunk mains and distribution mains. As WaterMet ${ }^{2}$ only adopts the connection between different element types, and not any connection from one type to each other (i.e. here SR to SR), this scheme was modified further as shown in Figure 3(b) to adapt to the conceptual model used in WaterMet ${ }^{2}$. Note that this modification was done such that logical links between source (i.e. water resource) and sink (i.e. sub-catchment) are preserved. Following this approach, the physical connection required for delivering water from R4 to LC1 in Reggio Emilia (in intervention strategy 2) is represented in these Figures by a green water main (link L12). For each of these links and storages, the energy and cost required per unit volume of delivered water is specified in the model. The energy comprises the total amount of energy required for treating or transferring (e.g. pumping) water between elements. Likewise, the fixed and variable costs, associated with operation and maintenance, are specified in the model. Among the plethora of data necessary to build the metabolism model, the capacity of each element of the system needs to be specified. The water capacity of each element is given in WaterMet ${ }^{2}$ as the maximum water volume per day which each element is able to transfer/treat/store. These capacities can be specified with the aid of physically based models. In this study, the capacity of elements was estimated by using the physical characteristics and corresponding flow rates calculated by the EPANET model of the case study and allowable flow velocities (Rossman, 2001). Thus, capacities of water mains were estimated by assuming the maximum flow velocity of pipeline $(1.8 \mathrm{~m} / \mathrm{s})$ as the limiting factor and taking into account trunks connecting more than one service reservoir (i.e. L6 in figure 3a). WTWs and water supply conduits were assumed to be large enough to treat the entire water inflow volume. Also no limitation was assumed here for groundwater abstraction over the planning horizon. Finally, the water flows in the built WaterMet ${ }^{2}$ model is calibrated with the resulted obtained from the corresponding EPANET model.

Table 2 Coefficients of water allocation between components in the WaterMet ${ }^{2}$ model for the BAU

\begin{tabular}{ll|ll|ll}
\hline $\begin{array}{l}\text { Connected } \\
\text { components }\end{array}$ & $\begin{array}{l}\text { Water allocation } \\
\text { coefficient }\end{array}$ & $\begin{array}{l}\text { Connected } \\
\text { components }\end{array}$ & $\begin{array}{l}\text { Water allocation } \\
\text { coefficient }\end{array}$ & $\begin{array}{l}\text { Connected } \\
\text { components }\end{array}$ & $\begin{array}{l}\text { Water allocation } \\
\text { coefficient }\end{array}$ \\
\hline SR1 from WTW1 & 0.378 & SR3 from WTW3 & 0.162 & SC1 from SR1 & 0.603 \\
SR1 from WTW2 & 0.460 & SR4 from WTW1 & 0.378 & SC1 from SR2 & 0.000 \\
SR1 from WTW3 & 0.162 & SR4 from WTW2 & 0.460 & SC1 from SR3 & 0.301 \\
SR2 from WTW1 & 0.347 & SR4 from WTW3 & 0.162 & SC1 from SR6 & 0.096 \\
\hline
\end{tabular}




\begin{tabular}{|c|c|c|c|c|c|}
\hline SR2 from WTW4 & 0.653 & SR5 from WTW4 & 1.000 & $\mathrm{SC} 2$ from SR2 & 0.300 \\
\hline SR3 from WTW1 & 0.378 & SR6 from WTW5 & 1.000 & SC2 from SR5 & 0.700 \\
\hline SR3 from WTW2 & 0.460 & & & SC3 from SR4 & 1.000 \\
\hline
\end{tabular}

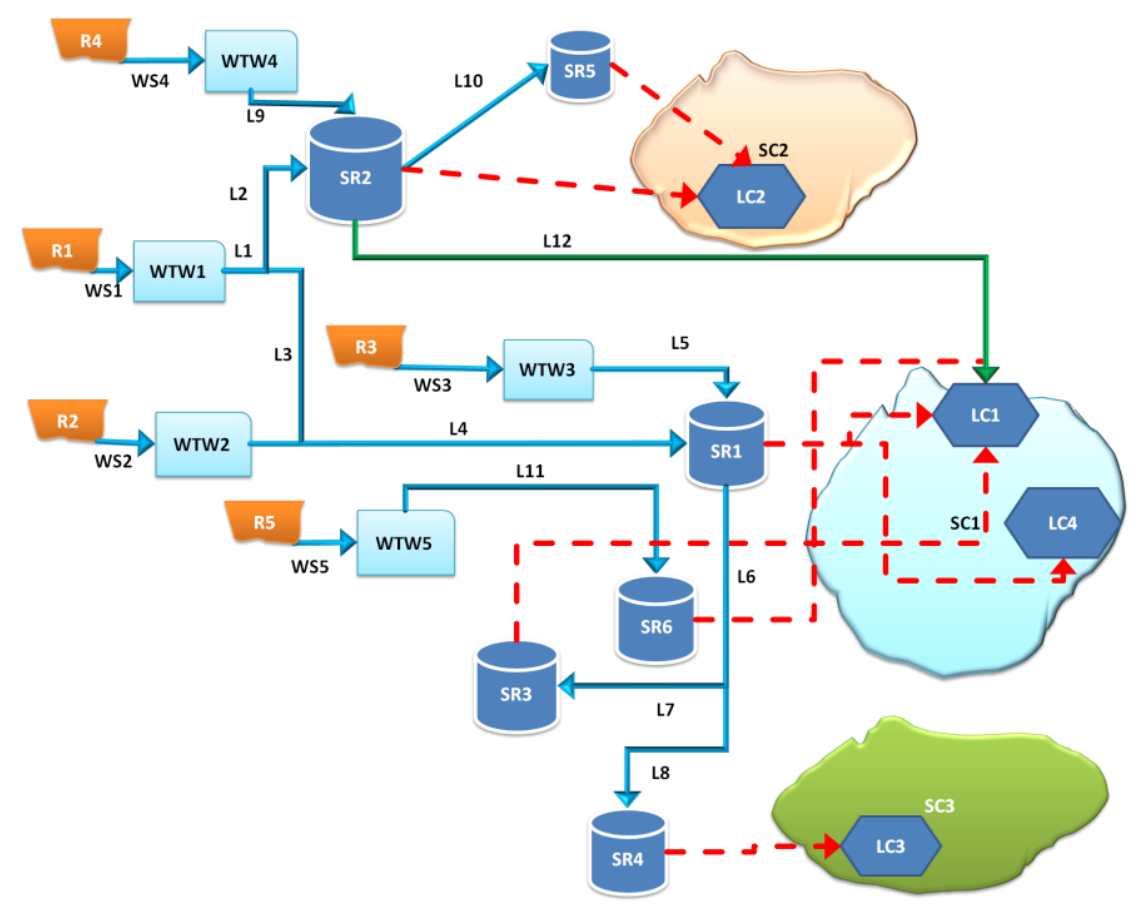

(a)

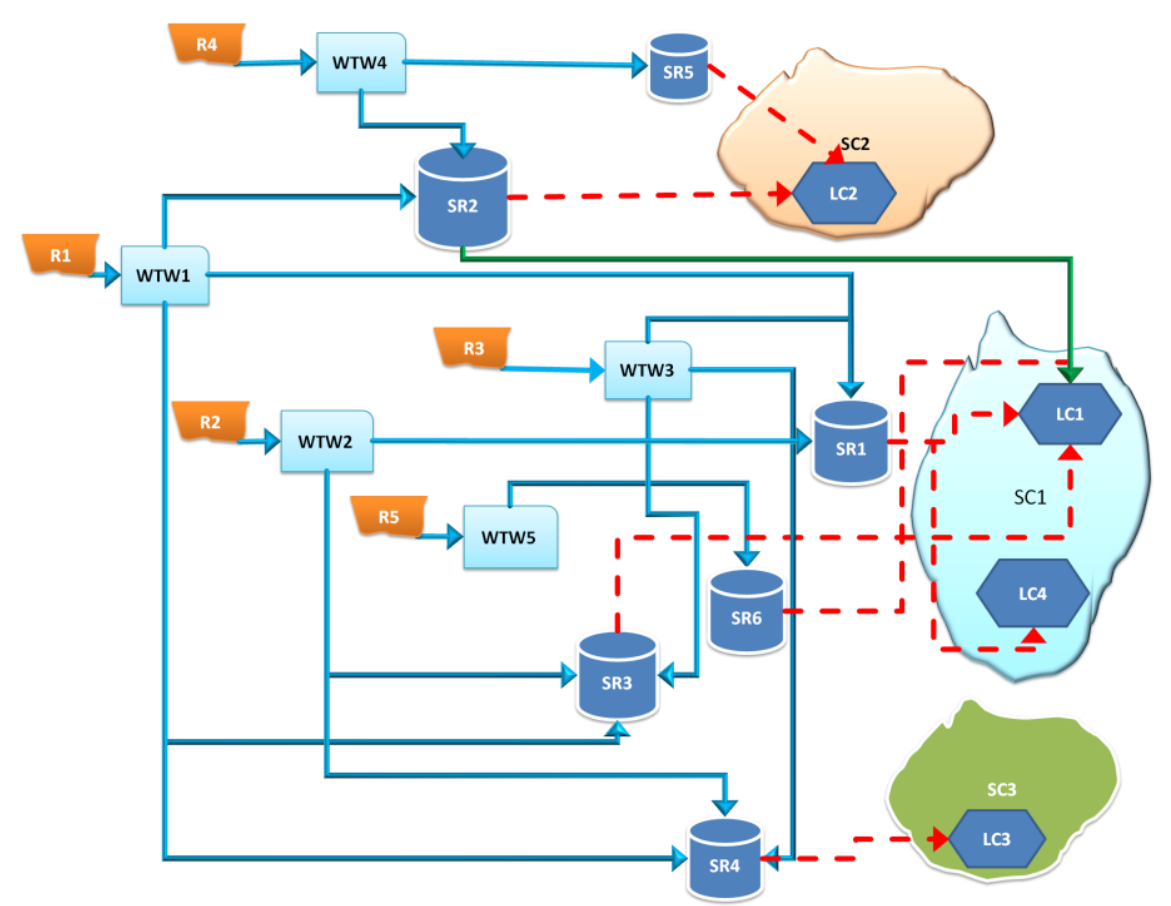

(b) 
Figure 3 Conceptualized scheme of the water supply system for (a) the water system in Figure 1 and (b) further modified for the resulting WaterMet ${ }^{2}$ model.

Water allocation coefficients between the components in WaterMet ${ }^{2}$ model for the BAU (strategy 1) are given in Table 2. In this strategy, sub-catchment 1 (Reggio Emilia) receives water from the three upstream service reservoirs (SR1, SR3 and SR6) and hence the relevant water allocation coefficient from SR2 is zero in the Table. However, by connecting SR2 to Reggio Emilia in strategy 2, it is assumed that the water main L12 (Figure 3) supplies $25 \%$ of the total demand of Reggio Emilia. Hence, the new water allocation coefficients in strategy 2 are: 0.452 for Reggio Emilia from SR1, 0.250 for Reggio Emilia from SR2, 0.226 for Reggio Emilia from SR3 and 0.072 for Reggio Emilia from SR6.

\section{RESULTS AND DISCUSSION}

The built WaterMet ${ }^{2}$ model was used to simulate the two aforementioned intervention strategies (i.e. strategy 1 and 2) under three scenarios of future population growth depicted in Figure 2 for a 30 year planning horizon. Figure 4 shows some of the calculated performance metrics for the BAU (intervention strategy 1) over the planning horizon. More specifically, variations of total water demand, fraction of water demand delivered, energy and GHG emissions for the entire water system (Reggio Emilia, Roncocesi and Rivalta) are shown in figures (a), (b), (c) and (d), respectively. Note that the leakage is included in the total water demand. Also energy required and corresponding GHG emissions result from consumed electricity, fossil fuel and embedded energy especially from chemicals used in the UWS components. As it can be seen, both energy and GHG emissions increase over the planning horizon according to increasing water demand. It should also be noted that the fluctuations of these indicators for extreme population growth (minimum and maximum) compared to the average values are up to around 5\% of the average values during the later years of the planning horizon.

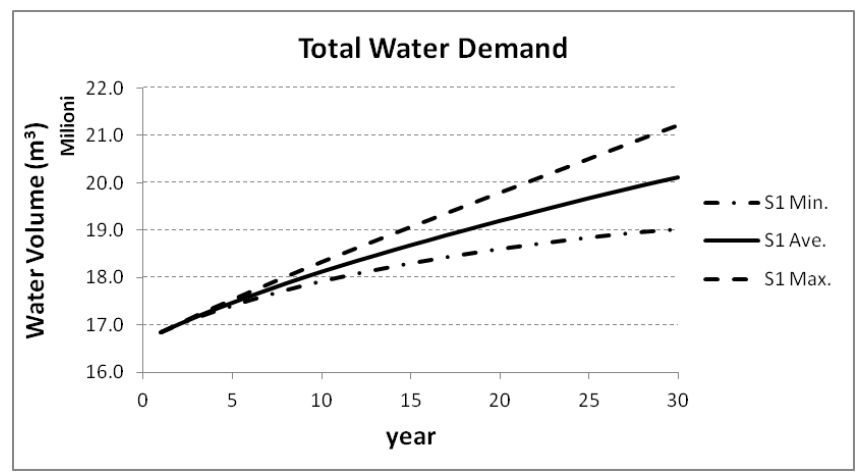

(a)

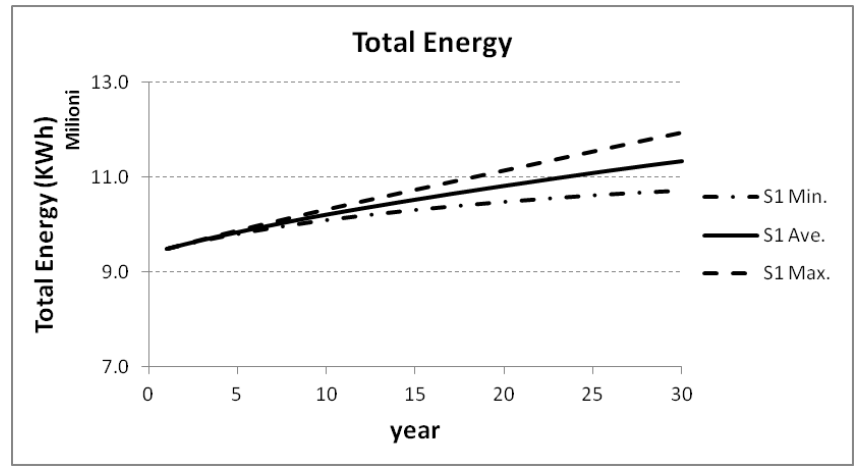

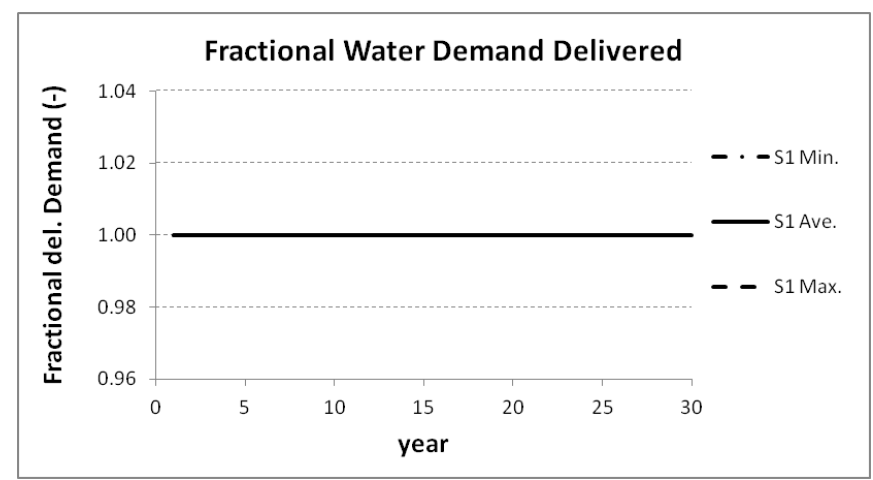

(b)

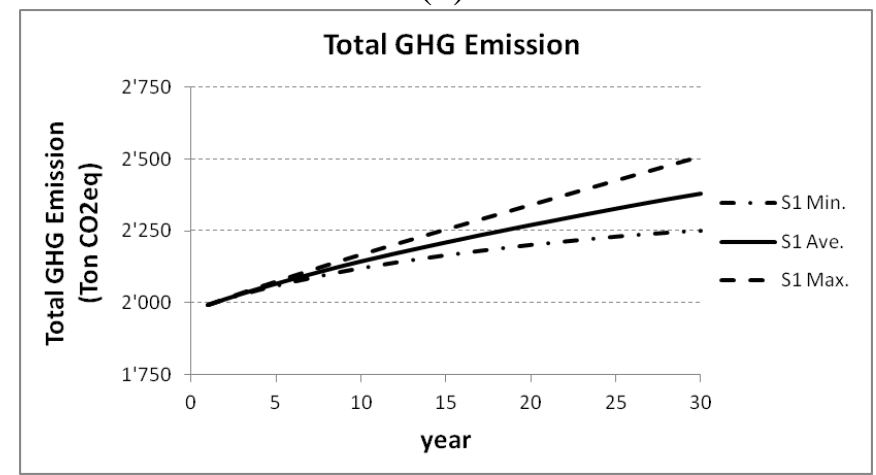


Figure 4 Performance indicators of the simulation for the BAU (strategy 1) for (a) total water demand; (b) fraction of water demand delivered; (c) total energy and (d) total GHG emissions.

Figures 5 (a)-(b) show respectively the total water demand and fraction of water demand delivered for strategy 2; as expected, both strategy 1 and 2 perform well in terms of total water demand (Figure 4 (a) and 5 (a)) and for fractional demand delivered (Figure 4 (b) and 5(b)). In fact, water resources are considered unlimited here for the two strategies as water abstraction for urban consumption in the case study is far smaller than agricultural water withdrawal from these resources and hence it is less likely to have a high impact on the results. For a more accurate analysis the estimation of the real water availability needs to be introduced in the model.

Figures 5 (c)-(d) show the difference over time between strategies 1 and 2 in terms of energy and GHG emissions for the entire water system (Reggio Emilia, Roncocesi and Rivalta). As it can be seen, the trend of the discrepancy between the performance indicators of the two strategies is increasing over the planning horizon. Also note that the impact of different population growth scenarios on the total energy is almost negligible, while the same fluctuations for GHG emissions are widening up to 0.5 ton $\mathrm{CO}_{2}$-eq compared to the average values during the later years of the planning horizon.

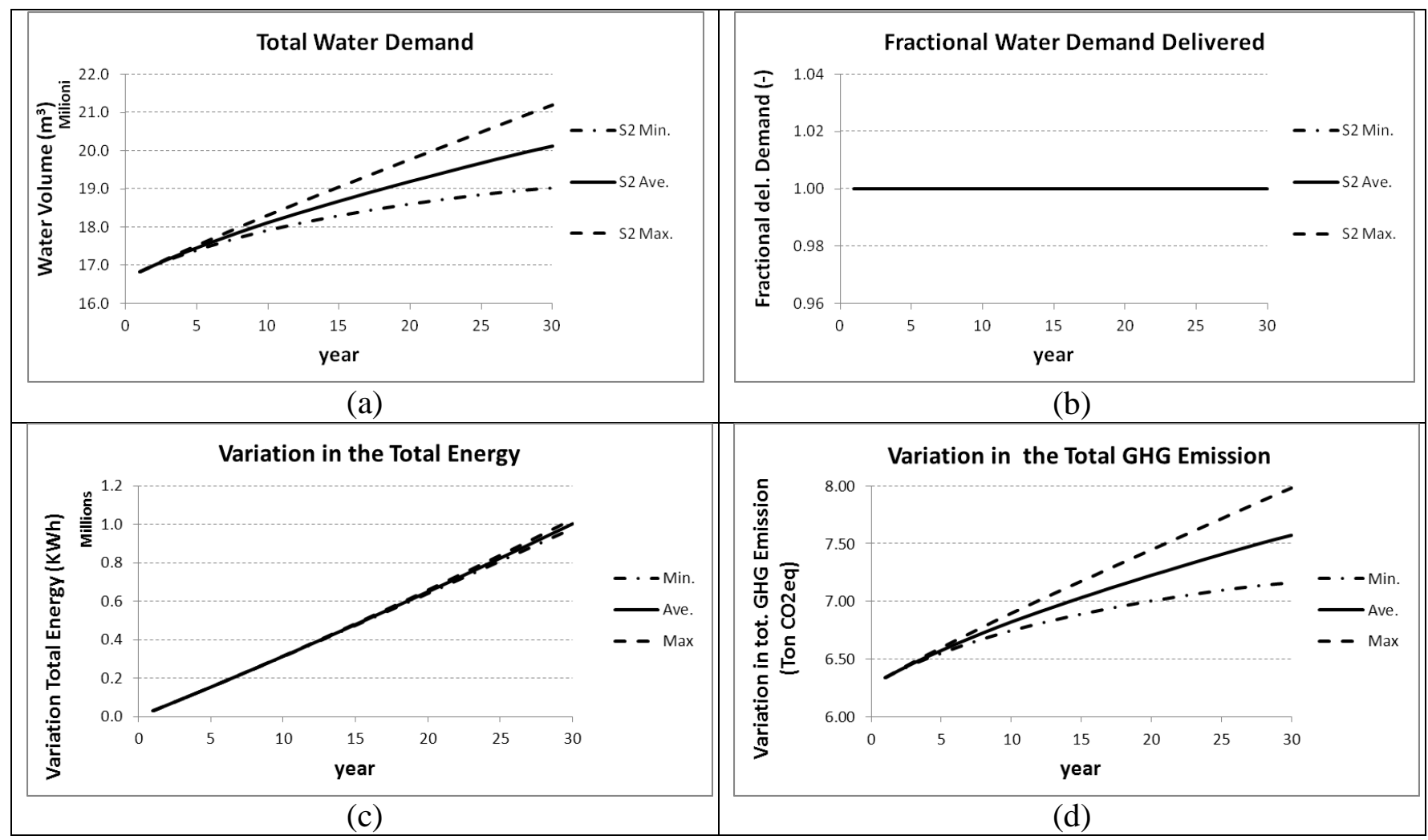

Figure 5 The total water demand and fractional demand delivered for strategy 2 are shown in (a) and (b) respectively. The differences between strategy 1 and strategy 2 in terms of total energy and total GHG emissions are shown in (c) and (d) respectively.

It is seen that the intervention strategy 2 outperforms the intervention strategy 1 with respect to the two selected metrics (GHG emission and Total energy); this is so despite the fact that implementing strategy 2 entails a more powerful pumping station in R4, as the overall hydraulic configuration is energetically more favourable for strategy 2. More specifically, Table 3 reports the cumulative differences between strategy 1 and strategy 2 in terms of three selected performance indicators (GHG 
emissions, total energy and cost) at some specific time horizons (i.e. year 1, 10, 20 and 30). Positive values indicate the benefit of adopting strategy 2 with respect to 1 .

The few metrics calculated by the WaterMet ${ }^{2}$ model in the water supply system of Reggio Emilia shows the capability of this kind of analysis, which can provide useful information for decision makers when analysing a number of different intervention strategies. In other words, having had the conceptual model of the water system along with future water demands and future objectives allows the evaluation of numerous intervention strategies and finally rank them in order to prioritise the most suitable ones.

Table 3 Cumulative differences between strategy 1 and strategy 2 in terms of energy, GHG and costs at different time horizons.

\begin{tabular}{c|ccc}
\hline Year & $\begin{array}{c}\text { Total Energy } \\
(\text { KWh })\end{array}$ & $\begin{array}{c}\text { GHG emissions } \\
(\text { Ton CO2-eq) }\end{array}$ & $\begin{array}{c}\text { Total } \\
\text { operational } \\
\text { cost }(\boldsymbol{\epsilon})\end{array}$ \\
\hline 1 & 30,180 & 6.3 & 1,512 \\
10 & 346,598 & 72.8 & 17,369 \\
20 & 649,582 & 136.4 & 32,552 \\
30 & $1,002,976$ & 210.6 & 50,261 \\
\hline
\end{tabular}

In this study, two intervention strategies, both compatible with the hydraulic constraints, have been compared with two selected metrics. The results show that strategy 2 weakly outperforms strategy 1 in terms of energy and GHG emissions. Moreover, strategy 2 may be more preferred as it provides an additional water source for the Reggio Emilia sub-catchment (SC1). This issue needs to be further investigated by a comprehensive risk analysis between these two strategies to reveal the effects of redundant capacity provided to the Reggio Emilia sub-catchment.

It should be noted that the intervention strategies evaluated here are not for the purpose of hydraulic/mechanical performances only but they can effects all the domains of the sustainability. As a result, reduction of operational costs will impact on the economic domain, the GHG emissions level will affect environmental domain, while the improvement of reliability will impacts on the social aspects. All these obtained impacts on the infrastructure are within the governance domain. The set of differences between the correspondent metrics calculated for intervention strategies in respect to the BAU scenario, provide a measure of the sustainability improvement.

\section{CONCLUSIONS}

The paper describes the application of a metabolism model, WaterMet ${ }^{2}$, to the water supply system of Reggio Emilia. WaterMet ${ }^{2}$ allows evaluating the level of sustainability of existing urban water systems and the impact of possible intervention options; hence it improves understanding on how decisions can contribute to meeting sustainability targets. Furthermore, adopting a comprehensive approach to the urban water systems, as when applying simplified mass balance analysis, requires the adoption of a number of simplifications for carrying out management steps. However, such approach turns out to be a powerful tool for long term strategic analysis and evaluation of intervention options under different scenario of change. The analysis shown would be difficult to complete using the physically-based model (e.g. EPANET) as this is data-intensive / demanding and not necessary at the strategic level of planning. The performance metrics (i.e. selection criteria) analysed are limited only to a number of key technical and environmental metrics that are of paramount importance to the Water Company and the public. Therefore, other criteria such as social impacts are not considered here as these need to be quantified by other tools and techniques outside the WaterMet ${ }^{2}$ model. The results obtained show that 
the built and calibrated WaterMet ${ }^{2}$ model allows a broader understanding of the impacts of alternative intervention strategies taking into account multidimensional aspects of the sustainability beside conventional service performance. This, in turn, can assist water authorities to verify the suitability of selected intervention strategies and to make more informed strategic decisions. Although the results could compare some aspects of the sustainability performance in the two analysed strategies, they cannot, at the current stage of work, be used to make any real decisions. To obtain a robust solution, the current model still needs to be further developed, tested and evaluated for multiple performance indicators including risk type ones as well as different intervention strategies. Finally, incorporating the analysis into a comprehensive Multi Criteria Decision Analysis (MCDA) will improve the comparison of the impact of scenarios of change on more dimensions of sustainability, than the few included in this example, and support even better decision makers.

\section{Acknowledgements}

The authors wish to acknowledge IREN Spa, for providing the data about the Reggio Emilia water supply system; C. Ziveri, P. Pedrazzoli, M. Cingi and F. Ferretti for their kindly support and for the fruitful suggestions and discussions about the water supply system functioning and for the review of the paper. This work was carried out as part of the 'TRansition to Urban water Services of Tomorrow' (TRUST) project. The authors wish to acknowledge the European Commission for funding TRUST project in the 7th Framework Programme under Grant Agreement No. 265122.

\section{References}

Alegre, H., Cabrera, E., Jr, Hein, A., Brattebø, H. (2012) Framework for Sustainability Assessment of UWCS and development of a selfassessment tool, TRUST, Deliverable D3.1.1, WA 3.

Arredi, F. (1990) Costruzioni Idrauliche, UTET, Torino.

Behzadian, K., \& Kapelan, Z. (2015a). Modelling metabolism based performance of an urban water system using WaterMet ${ }^{2}$. Resources, Conservation and Recycling, 99, 84-99.

Behzadian, K., Kapelan, Z., Venkatesh, G., Brattebø, H., Sægrov, S., Rozos, E., Makropoulos, C., Ugarelli, R., Milina, J., and Hem, L. (2013) Urban water system metabolism assessment using WaterMet ${ }^{2}$ model. In 12th International Conference on Computing and Control for the Water Industry, CCWI2013, vol. 15.

Di Federico, V., Makropoulos, C., Monteiro, A., Liserra, T., Baki, S., and Galvão, A. (2014) The TRUST approach for the Transition to Sustainability of Urban Water Services: the water scarcity cluster, In Intelligent Distribution for Efficient Affordable Supplies, Bologna, 22-24 October 2014.

Hein, A., Neskovic, M., Hochstrat, R., and Smith, H. (2012) Roadmap guideline: A manual to organise transition planning in Urban Water Cycle Systems, TRUST, Deliverable D13.1, WA 1.

ISTAT (2011) Previsioni demografiche - Anni 2011-2065 - dati pre-Censimento 2011 di fonte anagrafica. http://dati.istat.it/Index.aspx?DataSetCode=DCIS_PREVDEM.

Kennedy, C., Pincetl, S., and Bunje, P. (2011). The study of urban metabolism and its applications to urban planning and design. Environmental pollution, 159(8), 1965-1973.

Mackay, R., and Last, E. (2010) SWITCH city water balance: a scoping model for integrated urban water management. Reviews in Environ. Sci. and Bio/Technol. 9(4) 291-296.

Makropoulos, C.K., Natsis, K., Liu, S., Mittas, K., and Butler, D. (2008) Decision support for sustainable option selection in integrated urban water management. Environ. Model. \& Softw. 23(12) 1448-1460.

Mitchell, V.G., Mein, R.G., and McMahon, T.A. Modelling the urban water cycle. Environ. Model. \& Softw. 2001; 16(7) 615-629.

Mitchell, V.G., and Diaper, C. (2010) UVQ User Manual: (urban water balance and contaminant balance analysis tool), Version 1.2, CMIT Report No. 2005-282. CSIRO.

Pahl-Wostl, C. (2002) Towards sustainability in the water sector - The importance of human actors and processes of social learning. Aquatic Sciences, Volume 64, Issue 4, pp 394-411

Rossman, L, A. (2000) Epanet2 user's manual. U.S. Environmental Protection Agency, Cincinnati, USA.

Shove, E., and Walker, G. (2010) Governing transitions in the sustainability of everyday life, Research Policy, Volume 39, Issue 4, May 2010, Pages 471-476, ISSN 0048-7333, http://dx.doi.org/10.1016/j.respol.2010.01.019

Ugarelli, R., Almeida, M. C., Liserra, T., and Smeets, P. (2014a) Metabolism risk-controlled model, demonstrated by model for the city of Oslo, TRUST, Deliverable D32.1., WA3.

Ugarelli, R., Almeida, M.C., Behzadian, K., Liserra, T., Smeets, P., and Kapelan, Z. (2014b) Sustainability risk based assessment of the integrated urban water system: a case study of Oslo. In proc. of the 11th International Conference on Hydroinformatics - HIC 2014, New York City, USA. 
Van Leeuwen, C.J. (2013) City Blueprints: Baseline Assessments of Sustainable Water Management in 11 Cities of the Future. Water Resour. Manag., 27, 5191 - 5206.

Venkatesh, G., and Bratteb $\varnothing$, H. (2011) Energy consumption, costs and environmental impacts for urban water cycle services: Case study of Oslo (Norway). Energy 36(2) 792-800. 